\title{
Modulating innate immune activation states impacts the efficacy of specific $A \beta$ immunotherapy
}

Yona Levites ${ }^{1 *}$, Cory Funk ${ }^{2}$, Xue Wang ${ }^{3}$, Paramita Chakrabarty ${ }^{1}$, Karen N. McFarland ${ }^{1}$, Baxter Bramblett ${ }^{1}$, Veronica O'Neall, Xufei Liu', Thomas Ladd', Max Robinson², Mariet Allen ${ }^{4}$, Minerva M. Carrasquillo ${ }^{4}$, Dennis Dickson ${ }^{4}$, Pedro Cruz ${ }^{1}$, Danny Ryu' ${ }^{1}$, Hong-Dong Li ${ }^{5}$, Nathan D. Price ${ }^{2}$, Nllüfer Ertekin-Taner ${ }^{4,6}$ and Todd E. Golde ${ }^{1 *}$

\begin{abstract}
Introduction: Passive immunotherapies targeting A $\beta$ continue to be evaluated as Alzheimer's disease (AD) therapeutics, but there remains debate over the mechanisms by which these immunotherapies work. Besides the amount of preexisting $A \beta$ deposition and the type of deposit (compact or diffuse), there is little data concerning what factors, independent of those intrinsic to the antibody, might influence efficacy. Here we (i) explored how constitutive priming of the underlying innate activation states by 1110 and $\| 6$ might influence passive A immunotherapy and (ii) evaluated transcriptomic data generated in the AMP-AD initiative to inform how these two cytokines and their receptors' mRNA levels are altered in human AD and an APP mouse model.
\end{abstract}

Methods: $r A A V 2 / 1$ encoding EGFP, $\| 6$ or $\| 10$ were delivered by somatic brain transgenesis to neonatal (P0) TgCRND8 APP mice. Then, at 2 months of age, the mice were treated bi-weekly with a high-affinity anti-Aß1-16 mAb5 monoclonal antibody or control mouse lgG until 6 months of age. rAAV mediated transgene expression, amyloid accumulation, $A \beta$ levels and gliosis were assessed. Extensive transcriptomic data was used to evaluate the mRNA expression levels of IL10 and IL6 and their receptors in the postmortem human AD temporal cortex and in the brains of TgCRND8 mice, the later at multiple ages.

Results: Priming TgCRND8 mice with 1110 increases A $\beta$ loads and blocks efficacy of subsequent mAb5 passive immunotherapy, whereas priming with 116 priming reduces $A \beta$ loads by itself and subsequent $A \beta$ immunotherapy shows only a slightly additive effect. Transcriptomic data shows that (i) there are significant increases in the mRNA levels of 116 and 1110 receptors in the TgCRND8 mouse model and temporal cortex of humans with AD and (ii) there is a great deal of variance in individual mouse brain and the human temporal cortex of these interleukins and their receptors.

(Continued on next page)

\footnotetext{
* Correspondence: levites.yona@ufl.edu; tgolde@ufl.edu

'Department of Neuroscience and Neurology, Center for Translational Research in Neurodegenerative Disease, and McKnight Brain Institute, University of Florida, FL 32611 Gainesville, USA

Full list of author information is available at the end of the article
}

(c) The Author(s). 2021 Open Access This article is licensed under a Creative Commons Attribution 4.0 International License, which permits use, sharing, adaptation, distribution and reproduction in any medium or format, as long as you give appropriate credit to the original author(s) and the source, provide a link to the Creative Commons licence, and indicate if changes were made. The images or other third party material in this article are included in the article's Creative Commons licence, unless indicated otherwise in a credit line to the material. If material is not included in the article's Creative Commons licence and your intended use is not permitted by statutory regulation or exceeds the permitted use, you will need to obtain permission directly from the copyright holder. To view a copy of this licence, visit http://creativecommons.org/licenses/by/4.0/ The Creative Commons Public Domain Dedication waiver (http://creativecommons.org/publicdomain/zero/1.0/) applies to the data made available in this article, unless otherwise stated in a credit line to the data. 


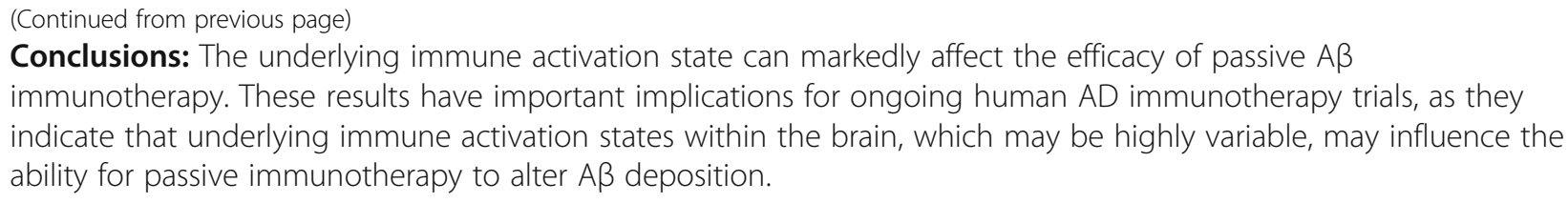

Keywords: Amyloid, Immunotherapy, Inflammation, II6, II10, IL6, IL10, Alzheimer's disease, Adenoassociated virus, RNA seq

\section{Introduction}

Accumulation of $A \beta$ aggregates in the brain parenchyma is hypothesized to trigger a complex neurodegenerative cascade that ultimately results in Alzheimer's disease $(\mathrm{AD})$. Based on this hypothesis there has been intense interest in therapeutic targeting of $A \beta$ and $A \beta$ aggregates [1-3]. Numerous immunotherapeutic approaches to targeting $A \beta$ have been evaluated in preclinical rodent models of $A \beta$ accumulation and multiple antibodies and active immunotherapies have advanced to clinical trials [4-10]. Indeed, preclinical studies have repeatedly established the disease-modifying potential of anti-A $\beta$ immunotherapy. However, the results to date from many human anti-A $\beta$ immunotherapy trials have been disappointing [11-16].

Data from the aducanumab phase $1 \mathrm{~b}$ study suggested that reductions of CNS amyloid, or at least the amyloid ligand PET signal, can be achieved in relatively short time-periods $[8,17,18]$. Though initial phase $1 \mathrm{~b}$ trial data suggested that this amyloid reduction might be associated with functional and cognitive benefits [8], the phase 3 trial targeting treatment in mild AD was initially halted due to lack of clinical efficacy [19]. However, more recent reanalysis of the trial with some additional data suggests clinical efficacy associated with the high dose treatment. These reanalyzed data, whose interpretation is controversial $[20,21]$, support a new biologic drug application that is currently being reviewed by the FDA. Similar reports of reduced amyloid PET ligand binding following immunotherapy have been reported with the antibody BAN2401 [19, 22], and phase 3 studies of this antibody in symptomatic $\mathrm{AD}$ are ongoing.

Even though amyloid ligand reduction binding has been observed, it is not yet clear how well this will correlate with alterations in amyloid levels in the postmortem brain. Further, it did not appear that everyone treated with these antibodies showed large reductions in the PET amyloid signal. Despite the lack of evidence for truly robust and universal efficacy in terms of slowing functional and cognitive decline, there is hope that $A \beta$ immunotherapies, with evidence for target engagement in humans, especially if used in the preclinical stages of $\mathrm{AD}$ or in primary prevention, could still show meaningful clinical efficacy [23].
However, there are still significant gaps in our understanding regarding the mechanism of anti- $\mathrm{A} \beta$ immunotherapies to reduce $A \beta$ deposition [24-29]. One of the original hypotheses regarding a peripheral sink induced by the high concentration of free antibody in the periphery has largely been ruled out [27, 30]. Indeed, even in humans, robust peripheral target engagement of soluble $\mathrm{A} \beta$ with the central domain monomer selective antibody, solanezumab, has failed to reduce amyloid plaques and was not associated with significant functional or cognitive benefit in mild $\mathrm{AD}[15,31]$. Both Fc-dependent and Fc-independent mechanisms have been proposed to underlie efficacy, and there is robust data generated using different anti-A $\beta$ antibodies and different preclinical models to either support or refute either mechanism [32-35]. Fc-dependent mechanism are purported to result in microglial activation and subsequent clearance of deposited $A \beta$. Fc-independent mechanisms likely work by binding aggregates and possibly interfering with subsequent aggregation, or enhancing efflux of the bound $A \beta$ engaged by the antibody in the brain to the periphery. One possible factor that may help to explain the different preclinical observations regarding $\mathrm{Fc}$-activation is that diffuse $A \beta$ deposits seem to be reduced more with antibodies that activate Fc receptors than do the more densely cored plaques [26, 35-37]. Notably, Fcdependent microglial activation following plaque engagement is the mechanisms of action proposed for aducanumab and supported by preclinical data with the murine version of that human antibody [8].

We and others have previously shown that altering innate immune activation states in the mouse brain via expression of cytokines, exposure to LPS or genetic manipulations can alter the time course of amyloid deposition in APP transgenic mice. Our internal data is consistent, showing that immune activating antiinflammatory cytokines decrease amyloid loads and immune inhibitory, anti-inflammatory cytokines increase amyloid [38-43]. Other data in the field creates a more confusing picture (reviewed in [44, 45]). Many published studies show similar data with pro-inflammatory manipulations, whereas other data show that activation of an anti-inflammatory state can reduce $A \beta$ accumulation or knockout of immune activating protein results in more 
amyloid deposition [38, 46-50]. Fewer immune manipulations have been reported in tau mice [51-53]. The handful of published studies suggest that there may be opposite effects of immune manipulations on $A \beta$ and tau pathology [54-56]. For example, manipulation of CX3CR1 and CX3Cl1 seem to have opposite effects on $\mathrm{A} \beta$ and tau pathologies [57].

One concern with all of the studies we collectively do in our mouse models of AD pathology is that they are kept in relatively sterile conditions (e.g., specific pathogen free housing), meaning that they are subject to limited immune priming $[58,59]$. Herein, we explored how immune priming via constitutive expression of Il6 or Il10 influenced subsequent passive $A \beta$ immunotherapy. We also evaluated how IL6 an IL10 and their receptors are altered at a transcriptomic level in (i) AD temporal cortex and cerebellar cortex in a large series of $\mathrm{AD}$ and Control brains and (ii) in longitudinal cohorts of APP TgCRND8 mice. We find that mAb5 passive immunotherapy alone and expression of rAAV-Il6 significantly attenuated $A \beta$ accumulation, whereas expression of rAAV-Il10 significantly increased $A \beta$ accumulation. rAAV-Il6 in combination with mAb5 resulted in a significant decrease in Thioflavin $S$ positive plaque counts compared to either intervention alone, but the effect was only slightly additive. In contrast, rAAV-Il10 preconditioning completely abrogated the beneficial effect of mAb5 immunotherapy on amyloid deposition. Large-scale transcriptomic data reveal that Il10 and Il6 and their receptors show quite variable expression in the brain, in both humans and mouse models. These results have important implications for ongoing human AD immunotherapy trials, as they indicate that underlying immune activation within the brain may influence the ability of passive immunotherapy to alter $A \beta$ deposition.

\section{Results}

\section{Overexpression of rAAV-II10 and II6 in the brain induce} robust gliosis

A schematic diagram of the experimental design used is shown in Fig. 1a. Briefly, we preconditioned TgCRND8 mice to express either mIL6 or mIL10 by P0 injection with $\mathrm{rAAV} 2 / 1$ vectors encoding these transgenes and began biweekly immunization with $\mathrm{mAb} 5$, an anti-A $\beta 1-$ 16 IgG2b antibody, at 2 months of age. Mice were euthanized at 6 months of age. We confirmed that brain

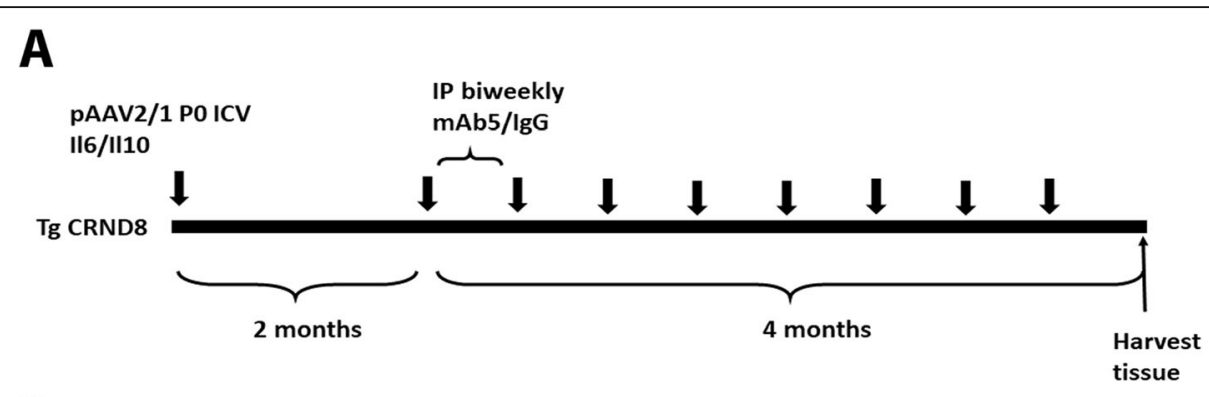

B
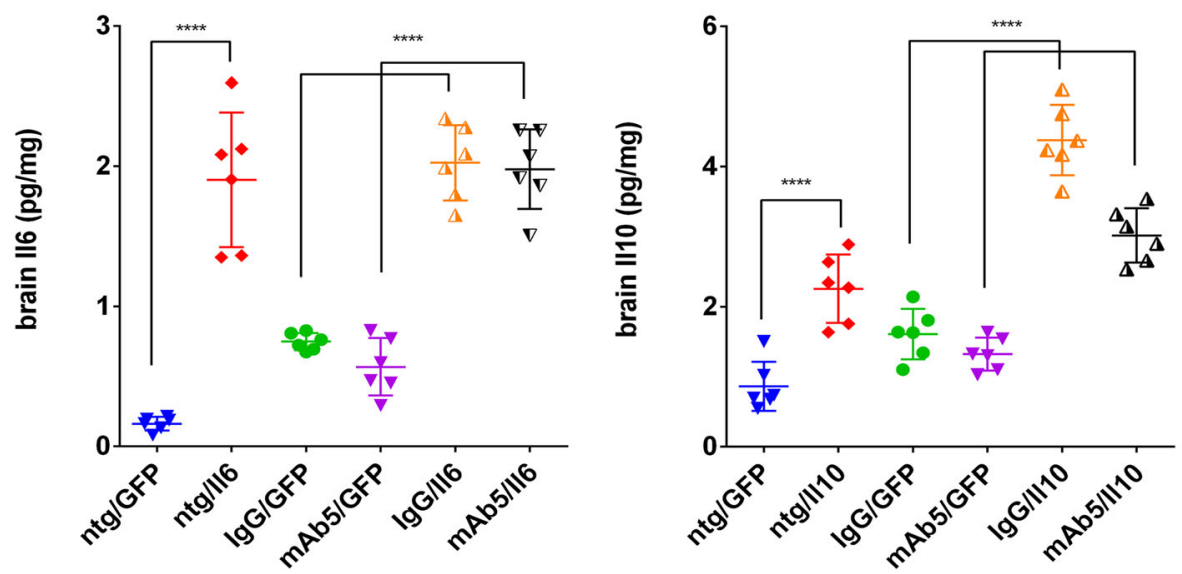

Fig. 1 II10 and II6 levels in the brain and plasma. a Schematic representation of experimental paradigm. Neonatal TgCRND8 mice were bilaterally injected ICV with pAAV2/1 ( $4 \times 10^{10}$ genomes) expressing $\| 6$ or $\| 10$ cytokines. Control mice were injected with pAAV2/1-GFP. At 2-months-old mice were divided into two groups that were immunized bi-weekly with $500 \mu \mathrm{g}$ of mAb5 or mouse $\operatorname{lgG}$. b 6-month-old mice were sacrificed and brains were harvested $(n=6-12)$. Brain levels of 116 and $\| 10$ were measured by ELISA. Data represent mean + SEM. ${ }^{*} p<0.01$, ${ }^{* *} p<0.001,{ }^{* * *} p<0.0001$ 
levels of Il6 and Il10 were increased even in 6-monthold mice (Fig. 1b) and showed that mAb5 or IgG control antibody treatment did not significantly alter expression levels of either cytokine. In previous studies, we noted that Il6 and Il10 altered gliosis, here we again assessed gliosis in all cohorts of mice. Staining with an IBA1 antibody reveals increased microgliosis in Il6 overexpressing brain in the cortex and hippocampus with no noticeable differences between groups immunized with mAb5 or control IgG (Fig. 2). Il10 overexpression increased IBA1 in the brains of overexpressing mice, and caused a slight morphological change with cells showing more amoeboid morphologies, especially around plaques. Il6 caused substantial increase in the amount of GFAP reactive astrocytes in the hippocampus and cortex, whereas Il10 caused a small but not significant increase in the GFAP staining. Interestingly, GFAP staining in mice overexpressing Il10 and treated with mAb5 is elevated as compared to control. Subgroup analysis showed no differences in responses of male versus female.

\section{Effects of Il6, mAb5, or both in combination on $A \beta$ deposition}

Both mAb5 and Il6 reduce A $\beta$ load, though the extent to which they alter $A \beta$ accumulation depends on the methodology used to assess deposition. When immunohistochemical methods were used to assess overall $A \beta$ deposition only the combination of mAb5 and Il6 showed a significant reduction $(p<0.01$, One-way Anova with Turkey's multiple comparison test) (Fig. 3a, b). When Thioflavin $\mathrm{S}$ was used to assess compact amyloid plaque number per section, there was a clear and significant reduction by $\mathrm{Il} 6$ alone and $\mathrm{mAb} 5$ in combination with $\mathrm{Il6}(p<0.001$ and $p<0.0001$, respectively) (Fig. 3c, d). Notably, the combination of mAb5 and Il6 reduced plaque number to a greater extent as compared to either treatment alone $(p<0.0001$ for mIL6 / mAb5 versus mAb5 alone and $p<0.01$ versus Il6 alone). In neither of these histochemical assessments does the reduction in $\mathrm{A} \beta$ deposition by $\mathrm{mAb} 5$ reach statistical significance. Assessment of biochemical loads showed that mAb5 treatment alone reduced SDS-insoluble formic acid solubilized (FA) A $\beta 40(p<0.01)$ and A $\beta 42(p<0.001)$, RIPA-insoluble SDS soluble (SDS) A $\beta 40(p<0.05)$ and A $\beta 42(p<0.01)$, and RIPA-soluble (RIPA) A $\beta 42(p<0.1)$ (Fig. 3e). Il6 alone also reduced $A \beta$ in these fractions compared to control as follows FA A $\beta 42(p<0.0001)$, SDS A $\beta 40(p<0.01)$ and A $\beta 42(p<0.0001)$, but did not have significant impact on RIPA soluble $A \beta$. The combination of mAb5 and 16 also reduced $A \beta$ compared to control: FA A $\beta 40(p<0.001)$ and $\mathrm{A} \beta 42(p<0.0001)$, SDS $\mathrm{A} \beta 40(p<0.01)$ and $\mathrm{A} \beta 42(p<0.0001)$, and RIPA $\mathrm{A} \beta 42$ $(p<0.01)$. In contrast to the histochemical measures, the biochemical analysis do not show statistical evidence for increased reductions in $A \beta$ loads with the combination of Il6 and mAb5 relative to either treatment alone.

\section{Effects of II10, mAb5, or both in combination on $A \beta$ deposition}

Overall, Il10 increased $A \beta$ loads and prevented the ability of $\mathrm{mAb} 5$ to reduce $A \beta$. For these studies, the effects of Il10 on immunotherapy were evaluated and compared to the same rAAV-EGFP control group and mAb5 treatment group. Il10 markedly increased immunohistochemical loads both in the absence and presence of mAb5 $(p<0.05$ for Il10 vs. GFP, and $p<0.01$ for Il10/AB5 vs. GFP) (Fig. 4a, b). There was no statistical difference in the increase in $\mathrm{A} \beta$ load, as detected by IHC, between the Il10 alone group and the mAb5/I110 group. When Thioflavin $\mathrm{S}$ was used to assess compact amyloid plaque number per section, there was a clear and significant increase by Il10 alone and mAb5 with Il10 combination $(p<0.0001$ for both), and there was no statistical difference in the increase in $A \beta$ between the Il10 treated group and the Il10 plus mAb5 treatment group (Fig. 4c, d). Assessment of biochemical loads showed that Il10 treatment alone increased FA $\mathrm{A} \beta 40(p<0.05)$ and A $442(p<0.0001)$, SDS A $\beta 42(p<$ $0.001)$, and RIPA A $\beta 42(p<0.05)$ (Fig. 4e). The combination of mAb5 and Il10 also increased FA A $\beta 42$ $(p<0.01)$ and SDS A $342(p<0.01)$ compared to control. Notably, there was no statistical difference in any of the fractions between the Il10 alone group and the Il10 plus mAb5 group.

Transcriptomic analysis of interleukins and their receptors It is well established that mouse models of amyloid deposition and human $\mathrm{AD}$ brain show large scale transcriptomic and pathologic alterations in immune pathways [60]. Here we have specifically mined data regarding RNAseq based mRNA levels of these interleukins and their receptors that was generated by our consortium (https://adknowledgeportal.synapse.org/ Explore/Projects?Grant\%20Number=U01AG046139) within the larger AMP-AD: Accelerating Medicines Partnership - Alzheimer's Disease Target Discovery and Preclinical Validation project (https://adknowledgeportal. synapse.org/Explore/Programs?Program=AMP-AD).

Notably, for both the human and mouse studies we had used high read depth (>100 M reads) to increase our ability to capture changes in low abundance mRNAs.

First, we examined mRNA expression of Il10, Il6, Il10ra (receptor subunit $\alpha$ ), Il10rb (receptor subunit $\beta$ ), Il6ra (receptor subunit $\alpha$ ), and Il6st (signal transducer) 

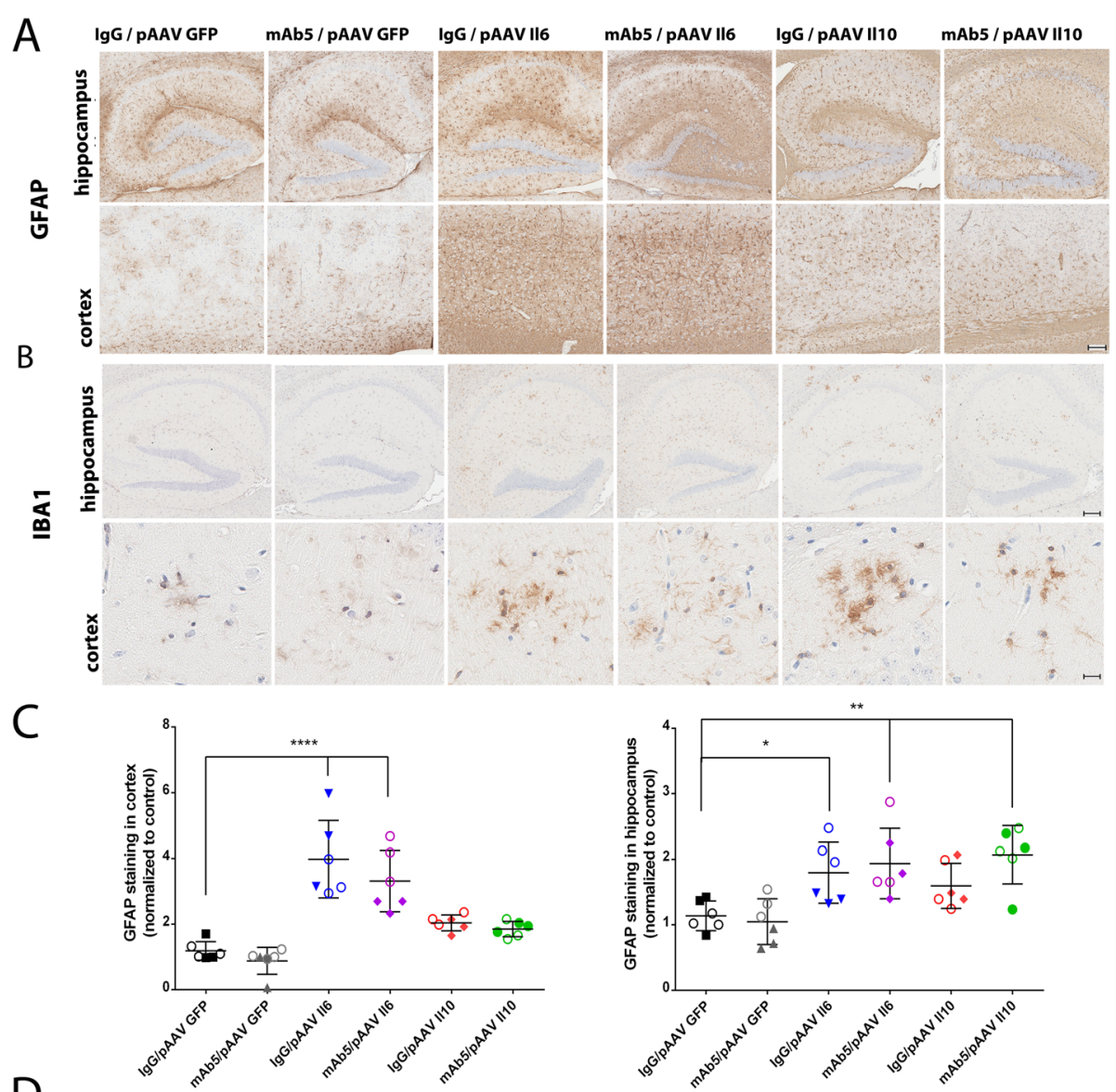

D
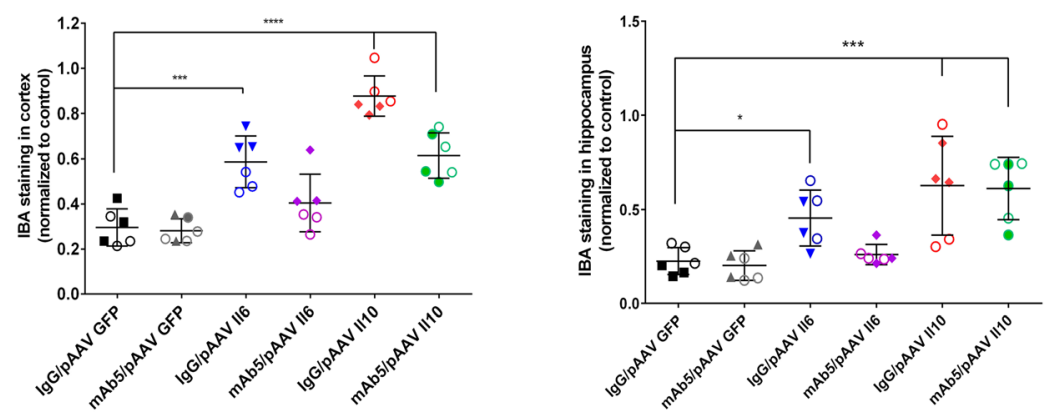

Fig. 2 Increased gliosis and astrocytosis as a result of 116 and $\| 10$ overexpression combined with mAB5 immunotherapy. a Up-regulation of activated glia was determined by IBA1 immunoreactivity in hippocampal (top panels) and higher magnification sections of cortex (bottom panels) of $116, \| 10$ and EGFP injected TgCRND8 mice immunized with anti-Aß mAb5 or mouse lgG. Abundant activated microglia are present in II6-injected mice compared with EGFP-expressing control mice, and even more so in II10 injected mice. mAb5 immunization had no significant effect on amount of activated microglia. Scale bars $=150 \mu \mathrm{m}$ (top); $45 \mu \mathrm{m}$ (bottom). b Activated astrocytes in the cortex of $\|6\|$,10 and EGFP injected TgCRND8 mice immunized with anti-A $\mathrm{mAb5}$ or mouse $\lg \mathrm{G}$ were detected by immuno staining of paraffin sections with rabbit polyclonal anti-GFAP antibody. Representative hippocampal sections (top panels) along with cortical sections (bottom panels) show a robust increase in the number of GFAP-positive neurons following 116 expression. Scale bars $=150 \mu \mathrm{m}$. $\mathbf{c}$, $\mathbf{d}$ Quantitative burden analysis of GFAP and IBA1 -positive cells in the cortex and hippocampus shows significant increase in 116 and $\| 10$ cohorts. The immunostaining was quantified from three sections from each mouse brain using Aperio imaging algorithms. Empty circles represent male mice, full symbols - females. $n=6,{ }^{*} p<$ $0.05,{ }^{* *} p<0.01,{ }^{* * *} p<0.001,{ }^{* * *} p<0.0001$, one-way Anova multiple comparison test

in TgCRND8 mice (APP KM670/671NL (Swedish), APP V717F (Indiana) compared to non-transgenic (non-Tg) mice at $3,6,12$, and 20 months of age. For reference we also include data on Cst7 and TREM2 as two of the more significantly upregulated immune DEGs in the TgCRND8 mice. These data reveal that both Il10 and Il6 are expressed at very low levels in the mouse brain. Despite average read depths of over 100 million counts, Il10 


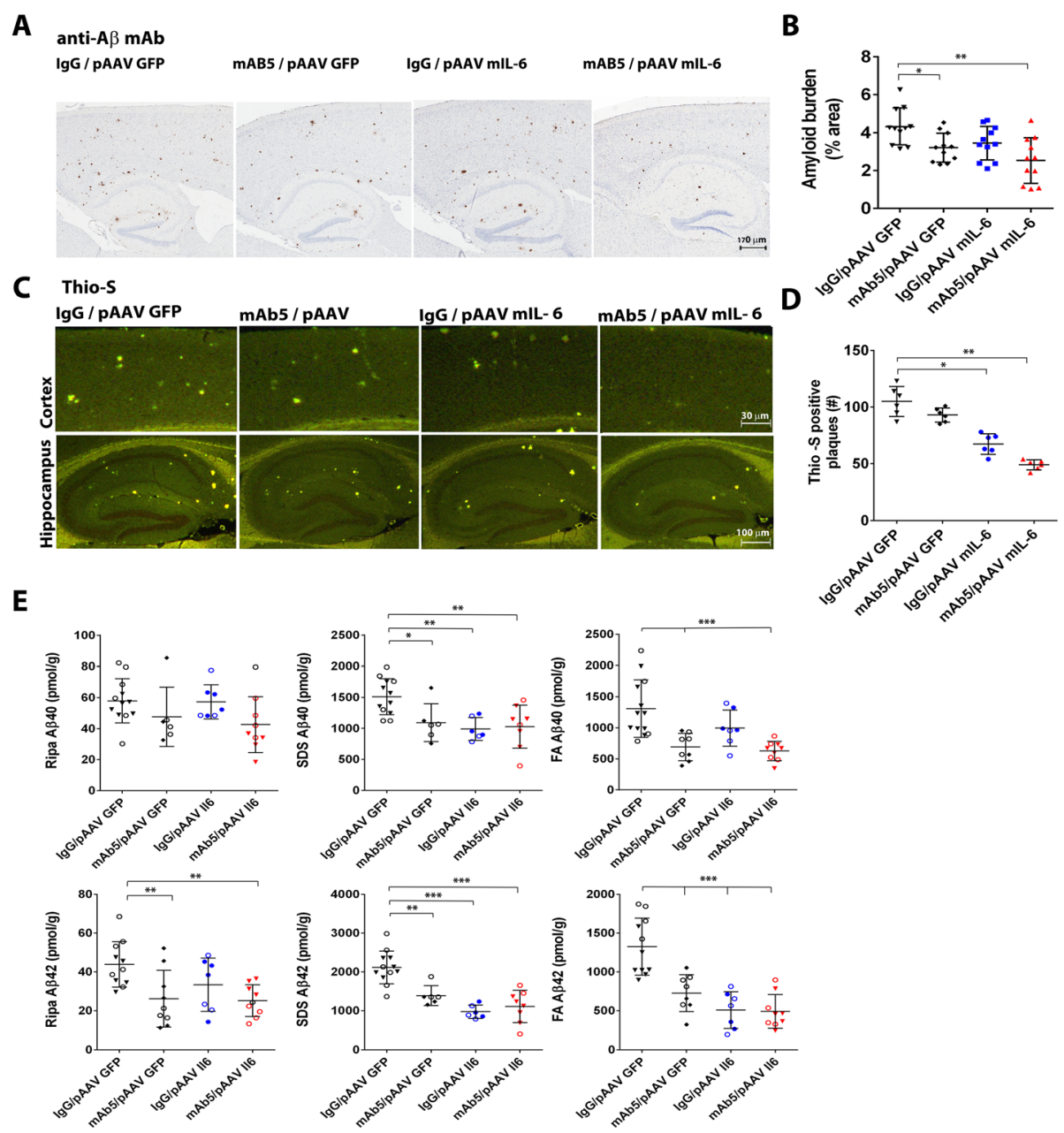

Fig. 3 Effects of 116 and Ab5 alone, or in combination on A $A$ deposition. a Representative brain sections stained with pan-A $A 1-16$ antibody (mAb 33.1.1) show $A \beta$ plaque immunoreactivity in the cortex and hippocampus of 6-month-old TgCRND8 mice expressing 116 or EGFP and immunized with mAb5 or mouse $\mathrm{lgG}$. Scale bar $=150 \mu \mathrm{m}$. b The immunostaining was quantified from three sections from each mouse brain using Aperio imaging algorithms. Combination of 116 overexpression and immunotherapy prevented plaque formation more, although not significantly, than each treatment individually. $n=5-7,{ }^{*} P<0.05 ;{ }^{*} P<0.01$. c Representative fluorescent cortical and hippocampal sections stained with Thio-S show A $\beta$ plaque immunoreactivity in the cortex and hippocampus of 6-month-old TgCRND8 mice expressing 116 or EGFP and immunized with mAb5 or mouse IgG. Scale bars $=150 \mu \mathrm{m}$. $\mathbf{d}$ The number of Thio-S positive cored plaques was quantified from three sections from each mouse brain. Combination of 116 overexpression and immunotherapy prevented plaque formation as well as 116 overexpression alone. e Biochemical analyses of FA, SDS and RIPA extractable A 342 and A 340 levels in 6-month-old II6-expressing TgCRND8 mice and EGFP-expressing age matched controls immunized with mAb5 or mouse IgG was performed by sandwich ELISA with anti AB40 and AB42 specific antibodies 2.13 and 13.1.1 as capture and 4G8-HRP as detection. Reduction in A $\beta$ levels was achieved with both II-6 overexpression and with immunotherapy, although a synergistic effect was not observed. Empty and full symbols represent male and female mice, respectively. $n=5-16,{ }^{*} p<0.05,{ }^{* *} p<0.01,{ }^{* * *} p<0.001$

mRNA is only detected in a few mice, and when it is detected the level is very low $(<0.1$ FPKM). Il6 is detectable in a majority of the samples, but again all FPKM values are low $($ FPKM $<0.2)$. In contrast to the levels of the cytokines themselves, their receptors are expressed at appreciable levels and show upregulation in the aging TgCRND8 mice brains. At 20 month of age Il10ra, Il10rb, Il6ra and Il6st show significantly increased expression compared to non-Tg mice, with Il10rb also showing significant upregulation in 12month TgCRND8 mice brains (Fig. 5). Notably, this upregulation at the
mRNA level is not as dramatic as that of other genes that are known to be quite selectively expressed on microglial cells. Indeed, many mRNAs, illustrated by Trem 2 and Cst7 are markedly and significantly, upregulated at early ages in the TgCRND8 mice brains, and continue to increase in levels as the mice age. For the human data, we focused on a set of $80 \mathrm{AD}$ and 69 control temporal cortex samples that had passed our RNAseq quality control. IL10 and IL6 were again generally expressed at low levels. However, in this case a number of the samples $(\sim 15 \%)$ showed expression of IL10 and 


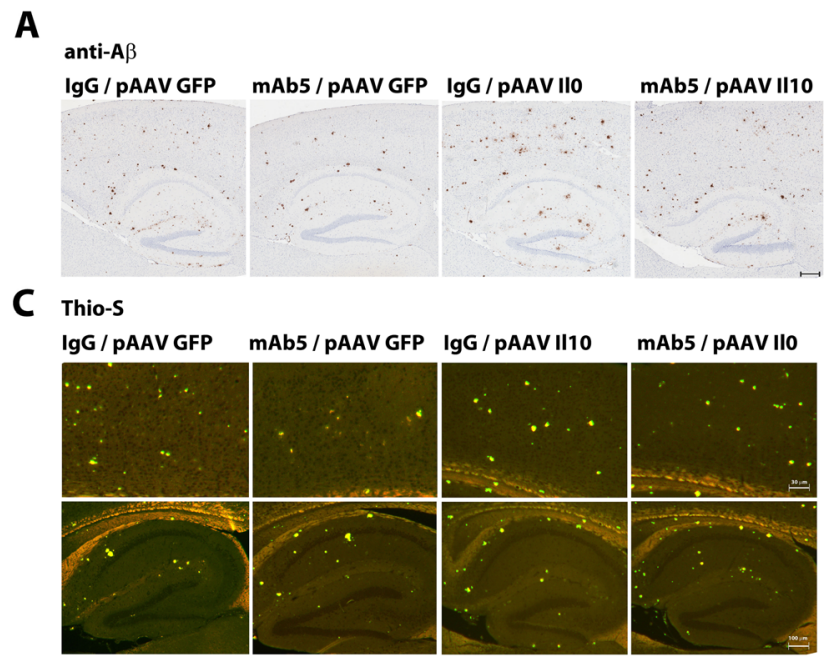

$\mathbf{E}$
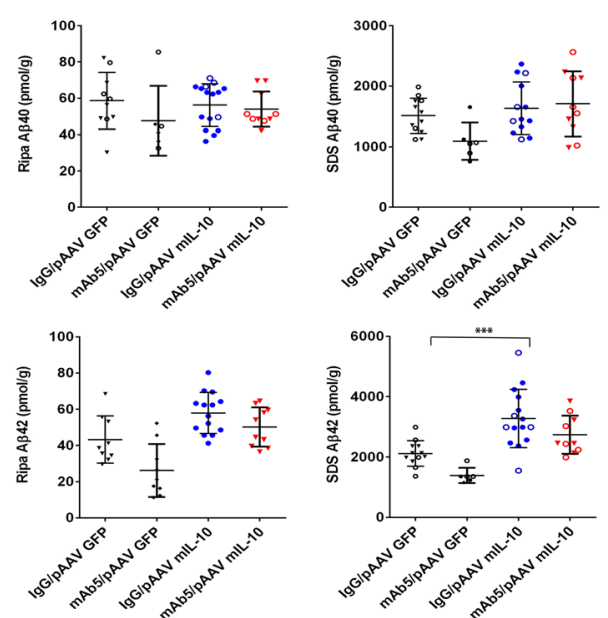

B
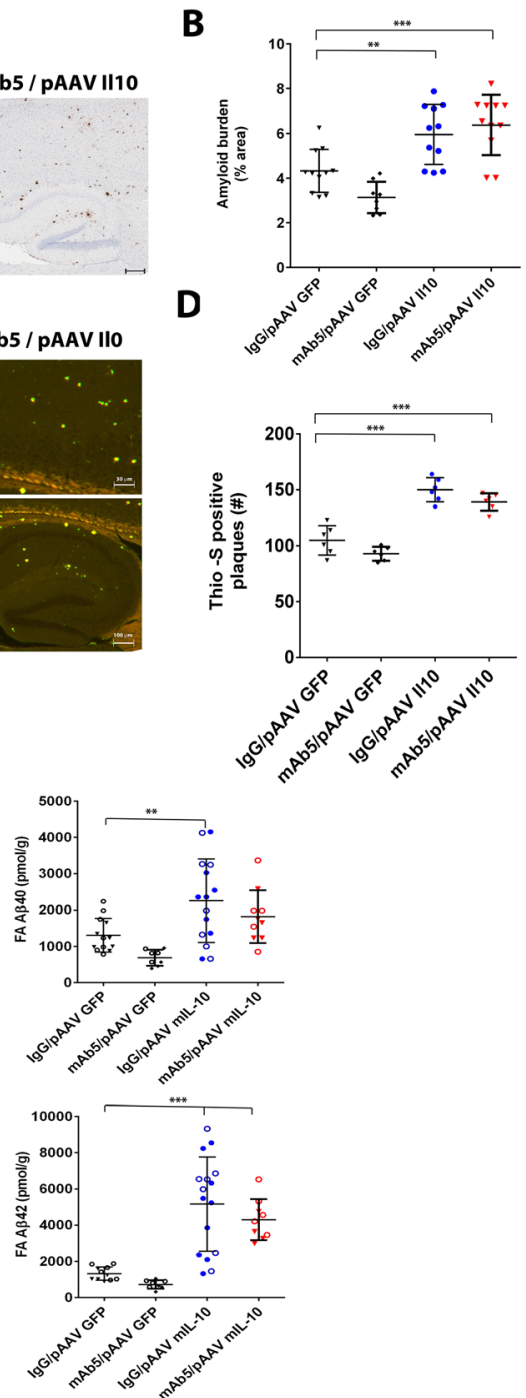

Fig. 4 Effects of $\| 10$ and mAb5 alone, or in combination on A deposition. a $\| 10$ abolishes the effect of immunotherapy on amyloid loads. Representative brain sections stained with pan-Aß1-16 antibody (mAb 33.1.1) show A $\beta$ plaque immunoreactivity in the cortex and hippocampus of 6-month-old TgCRND8 mice expressing 1110 or EGFP and immunized with mAb5 or mouse lgG. Scale bar $=150 \mu$ m. b The immunostaining was quantified from three sections from each mouse brain using Aperio imaging algorithms. Combination of II10 overexpression and immunotherapy resulted in increased plaque formation. $n=5-16,{ }^{*} P<0.05 ;{ }^{* *} P<0.01$. c Overexpression causes an increase in number of Thio-S positive plaques. 1110 overexpression abolished the effects of mAb5 immunotherapy on reduction in the number of Thio-S positive plaques. d Representative fluorescent cortical and hippocampal sections stained Thio-S show A $\beta$ plaque immunoreactivity in the cortex and hippocampus of 6-month-old TgCRND8 mice expressing 1110 or EGFP and immunized with mAb5 or mouse lgG. Scale bars $=150 \mu$ m. B. The number of Thio $S$ positive cored plaques was quantified from three sections from each mouse brain. e $\| 10$ overexpression-induced increase in $A \beta$ levels is observed in in cohorts immunized with either mAb5 or mouse IgG as demonstrated by sandwich ELISA with anti A 40 and 42 specific antibodies 2.13 and 13.1.1 as capture and 4G8-HRP as detection. Immunotherapy had no effect on A $\beta$ levels in $\| 10$ overexpressing mice. $n=5-16,{ }^{*} p<0.05$, ** $p<$ $0.01,{ }^{* *} p<0.001$. Empty and full circles represent male and female mice, respectively

IL6 $(\sim 55 \%)$ at levels higher than a cqn of -1 . Both IL10 $(\mathrm{p}=0.06)$ and IL6 $(\mathrm{p}=0.02)$ showed trends towards increased in AD but these changes did not withstand correction for false discovery. IL10RA, IL6R, and IL6ST mRNA levels were all significantly increased in the AD temporal cortex, as were CST7 and TREM2 mRNA levels (Fig. 6).

\section{Discussion}

We have found that preconditioning with Il6 or Il10 dramatically alters the effects of subsequent passive $A \beta$ immunotherapy with the anti-A $\beta$ antibody mAb5. Although a modest additive effect on one measure of $A \beta$ deposition, (decreased Thioflavin $S$ plaque count) was observed with Il6 preconditioning and subsequent mAb5 


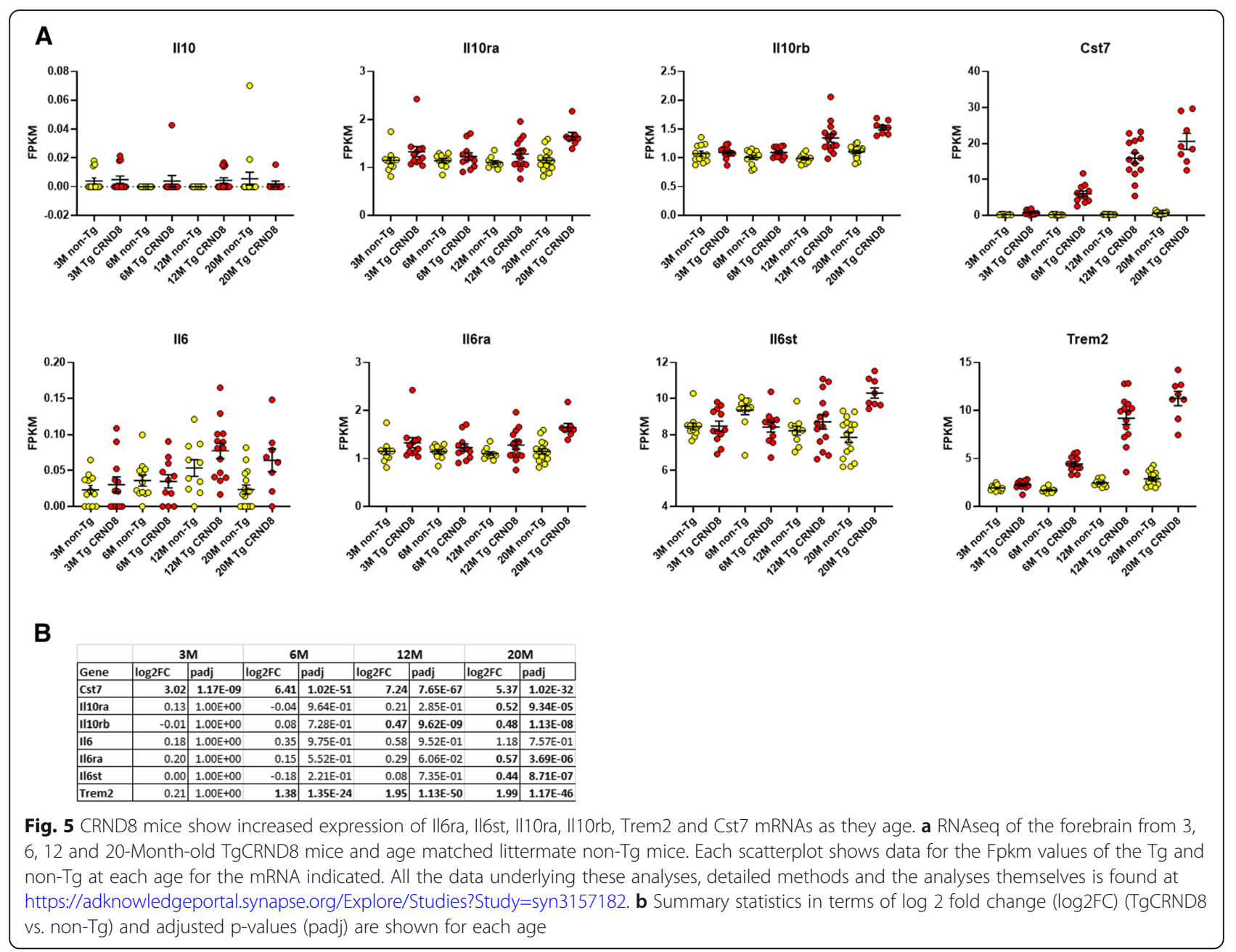

immunotherapy, Il10 preconditioning blocked the subsequent impact of mAb5 immunotherapy. The data has a high degree of validity as each of the manipulations by themselves replicated findings from our previous work $[30,38,41]$. Il10 expression increased $A \beta$ deposition and astrocytosis. Il6 expression decreased $A \beta$ deposition and produced both an astrocytosis and microgliosis. mAb5 immunotherapy alone decreased $A \beta$ deposition to some degree without appreciable effect on astrocytes or microglial cells. In our previous studies, we had not performed a simultaneous comparison of the effect of $\mathrm{Il}$ and mAb5 immunotherapy, though our impression from those studies was that 116 reduced $A \beta$ almost as well as a passive $A \beta$ immunotherapy $[30,41]$. Here, we confirm that impression, and note that both treatments reduce $A \beta$ deposition nearly to the same degree. The combination of Il6 and mAb5 shows no evidence for being synergistic and only appears to be partially additive, as the only significant impact of both Il6 and mAb5 together is on the number of Thioflavin $\mathrm{S}$ positive cored plaques.
There are a few caveats and limitations to this study. First, we have only evaluated the effects of preconditioning on the subsequent efficacy of a single anti- $A \beta$ mAb. It is possible that other anti-A $\beta$ mAbs, may be influenced to a greater or lesser degree by the immune preconditioning. Second, we have not looked at multiple time points. As we have previously shown that increased plaque load at time of immunization reduces efficacy of that therapy by itself, we would not expect that longer studies would appreciably alter the findings with Il10 preconditioning. It is, however, possible that longer treatment with both $\mathrm{Il6}$ and mAb5 might show more robust effects of the combination. Third, we powered these studies to be able to detect effects on $\mathrm{A} \beta$ deposition, and the group sizes were not sufficient to evaluate behavioral impacts.

We have previously shown that suppression of an inducible mutant APP transgene in combination with passive anti-A $\beta$ immunotherapy results in true clearance, not just suppression of ongoing deposition, of both the more diffuse $A \beta$ deposits surrounding cored plaques as 


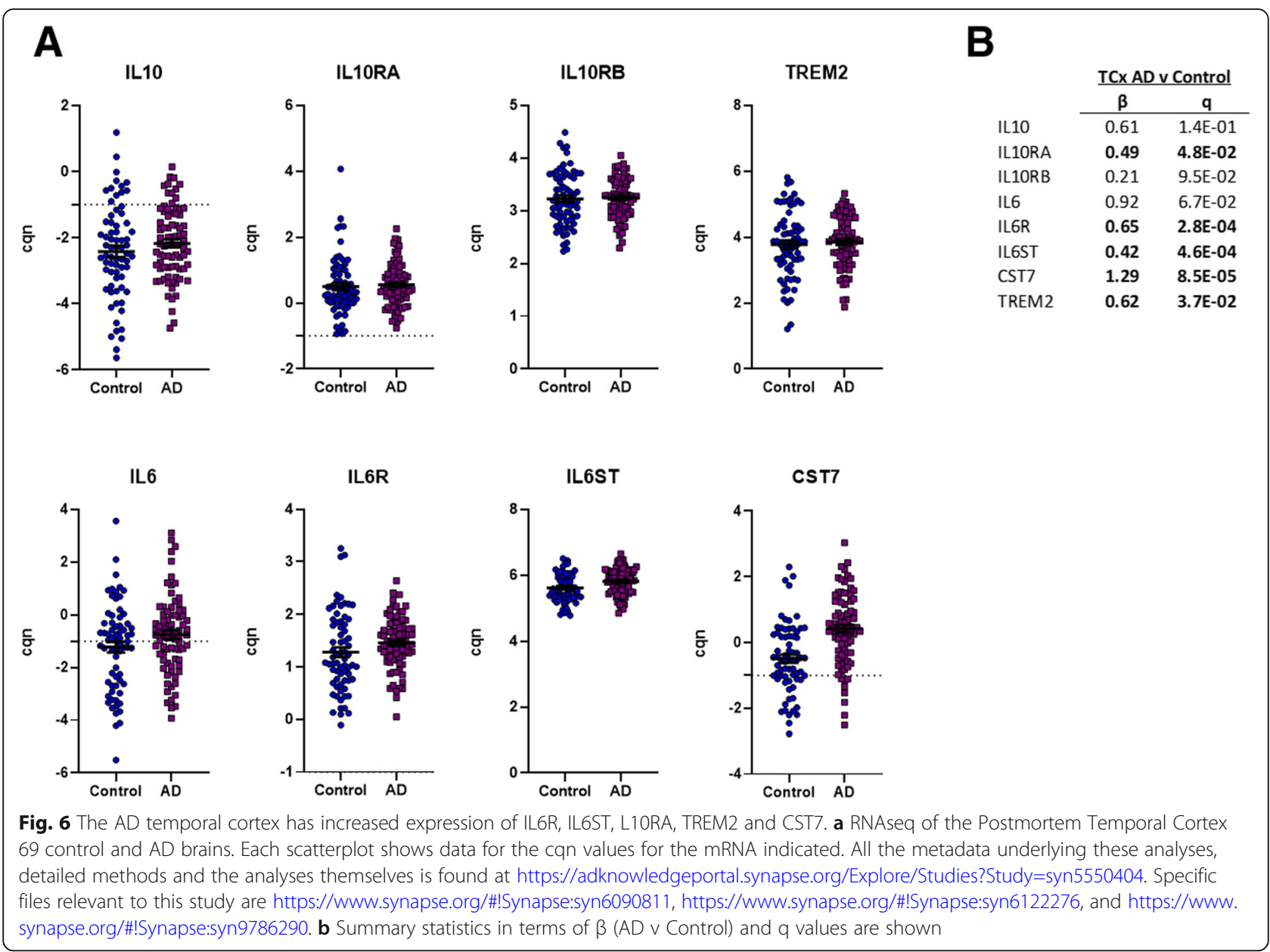

well as smaller non-dense core plaques. A similar study in the same inducible APP model, again shows that Il6 had a similar effect [61]. These data along with our data on Il6 preconditioning with subsequent mAb5 immunotherapy suggest that at least partially additive effects on $\mathrm{A} \beta$ accumulation and possibly clearance can be achieved through combinations of blocking $\mathrm{A} \beta$ production, aggregation and clearance.

Il10 preconditioning may abrogate the effect of subsequent $A \beta$ immunotherapy through several non-exclusive mechanisms. Given our previous work and that of others showing the reduced efficacy of immunotherapy in mice with higher amyloid loads, it may simply be that Il10 increases $A \beta$ deposition to the point that subsequent mAb5 administration is no longer effective [24, 58, 62$64]$. We have also catalogued a large number of transcriptomic changes and functional alterations in microglial cells and microglial phagocytosis attributable to Il10 brain overexpression. Such complex changes induced by Il10 may also contribute to the lack of efficacy of subsequent passive immunotherapy.

The efficacy of immune checkpoint inhibitors in cancer is clearly influenced by the local tumor immune microenvironment [65] Herein, we have utilized publicly available transcriptomic data that we have generated to explore the notion that changes and variability in the immune system in individual human or mice brains might be an extrinsic factor that could alter responses to an anti-A $\beta$ targeted immunotherapy. Taking a simplistic approach to this issue, we focused on how the cytokines studied herein and their receptors are altered both temporally in a mouse model of amyloid $A \beta$ deposition and by the AD state. First, these data show that there are significant increases in the cytokine receptors mRNA levels in the TgCRND8 mouse model and in the temporal cortex of humans with AD. However, these receptor RNAs are not as robustly upregulated as much as some other microglial genes (e.g. TREM2, CST7). Second, these data show that in the mouse brain mRNAs for Il10, which is almost undetectable, and $\mathrm{Il} 6$ are expressed at much lower levels on average than their receptors. In human temporal cortex the difference between level of cytokine and level of receptor is not as large, but still appreciable. The relatively low levels of these cytokines mRNAs compared to their receptor mRNAs, prompt a number of intriguing questions that will need to be pursued in future 
studies. These include: Are these differences reflected at the protein level? How can such typically low levels of cytokines robustly engage the receptor? Is the periphery, typically, a primary or at least significant source of Il6 and Il10 in the brain? Third, and perhaps most striking, is that there is a great deal of variance in individual mouse brains and even more so in the human temporal cortex with respect to the relationship between the expression of IL6 and IL10 and the high affinity receptors IL6R and Il10RA. We believe this later feature is highly relevant to our experimental studies. Such data shows that in the individual human control or AD brain, there is a high degree of variability in the activation state of the immune system. Given our current data that Il10 and Il6 differentially alter the subsequent effects of antiA $\beta$ immunotherapy, we hypothesize that variation in innate immune activation states within the human brain, may contribute to the variability in response to an $A \beta$ targeting immunotherapy, at least with respect to the effects on clearance of $A \beta$.

Of course, by themselves the variable levels of these select cytokines and receptors do not necessarily inform on the functional status of the immune system within the brain. Additional systems level multiomic studies including single cell studies and more comprehensive algorithms to predict immune status may help illuminate a set of biomarkers that better define, at an individual level, the brain's immune status [66-68]. Ex vivo analysis of the immune microenvironment within a tumor has demonstrated utility in understanding how well immune checkpoint inhibitors may work. The lack of direct access to brain tissue in the AD field makes it much more challenging to assess immune status in an individual AD brain. Additional CSF and imaging biomarkers that better track innate immune status will be needed to better understand the influence of innate immune status on outcomes of anti-A $\beta$ immune therapy [69].

In summary, our experimental data show that altering the brain's immune activation state by priming with cytokines that have different effects by themselves on $A \beta$ deposition can markedly impact the efficacy of subsequent passive anti-A $\beta$ immunotherapy. These results have important implications for ongoing human AD immunotherapy trials, as they indicate that underlying immune activation states within the brain, which at least in the postmortem brain appear to be highly variable, may influence the ability of passive immunotherapy to alter A $\beta$ deposition.

\section{Methods}

\section{Animal models and AAV injection}

Mice. All animal husbandry procedures performed were approved by the Institutional Animal Care and Use Committee. TgCRND8 were maintained as described before [70], transgenic males were crossed with B6C3F1 ntg females.

rAAV2/1 viruses for ICV injections expressing Il6 and Il10 under the control of the cytomegalovirus enhancer/chicken $\beta$ actin promoter were generated as described previously [41]. Briefly, AAV vectors expressing the cytokines under the control of the cytomegalovirus enhancer/chicken beta actin (CBA) promoter, a WPRE, and the bovine growth hormone polyA were generated by plasmid transfection with helper plasmids in HEK293T cells. $48 \mathrm{~h}$ after transfection cells were harvested and lysed in the presence of $0.5 \%$ Sodium Deoxycholate and $50 \mathrm{U} / \mathrm{ml}$ Benzonase (Sigma) by freeze thawing, and the virus isolated using a discontinuous Iodixanol gradient, and affinity purified on a HiTrap HQ column (Amersham). The genomic titer of each virus was determined by quantitative PCR.

Neonatal rAAV injections and antibody treatment. TgCRND8 mice were injected with $2 \mu$ l of rAAV ICV into the both hemispheres using a $10 \mu$ l Hamilton syringe with a $30 \mathrm{~g}$ needle on day P0 (Il10) or P1 (Il6) as described before $[38,41]$ and aged till 2 months. They were then divided into two gender-matched cohorts, and immunized bi-weekly i.p. with mAb5 (IgG2b) or mouse IgG (0.5 mg/per mouse) diluted in $0.9 \%$ saline, for 4 months, a regimen that was established in [30] .

Measurement of $\mathrm{Il} 6$ and Il10 in the brain and plasma. Brains from mice injected with rAAV Il6 and Il10 were sagitally dissected and the left hemisphere was snap-frozen in isopentane. They were then homogenized at a concentration of $150 \mathrm{mg} / \mathrm{ml}$ and sequentially extracted with protease inhibitor cocktail (Roche) in RIPA buffer, $2 \%$ SDS buffer, and $70 \%$ formic acid (FA) as described previously.

Sandwich capture Il6 ELISA assays using RIPA soluble lysates were done with mouse specific reagents (BD Biosciences). The same procedure was performed on plasma from injected mice.

A $\beta$ levels from the $2 \%$ SDS- and $70 \%$ FA-extracted samples were quantified using end-specific sandwich ELISA as previously described [71]. A $\beta 40$ was captured with mAb 13.1 .1 (human A $335-40$ specific; T.E. Golde) and detected by HRP-conjugated mAb 33.1.1 (human A $\beta 1-16$; T.E. Golde). A $\beta 42$ was captured with $\mathrm{mAb}$ 2.1.3 (human A $335-42$ specific; T.E. Golde) and detected by HRP-conjugated mAb 33.1.1 (human A $\beta 1-16$; T.E. Golde). ELISA results were analyzed using SoftMax Pro software.

Immunohistochemical imaging and image processing. Right hemibrain was fixed in $4 \%$ paraformaldehyde. Immunohistochemical staining was done using pan $A \beta$ antibody 33.1.1 (1:1500, T. Golde), Iba-1 (1:1000; Wako), GFAP (1:500; Chemicon). 1 \% Thioflavin S (Sigma) staining was done on paraffin embedded brain sections using 
established protocols. Immunohistochemically and fluorescent stained sections were captured using the Aperio Scanscope XT or FL image scanner and analyzed using either Aperio positive pixel count or ImageJ program. Brightness and contrast alterations were applied identically on captured images using Adobe Photoshop CS3.

Quantification of $\mathbf{A} \boldsymbol{\beta}$ deposition and gliosis. Immunohistochemically and fluorescent stained sections were captured using the Scanscope XT or FL image scanner (Aperio) and analyzed using ImageScope program. $A \beta$ plaque burden and intensity of astrogliosis staining was calculated using the Positive Pixel Count program (Aperio). At least three sections per sample, $30 \mu \mathrm{m}$ apart, were averaged by a blinded observer to calculate plaque burden. For Thioflavin S quantitation, one section per sample was used by a blinded observer to manually count the plaques using Adobe Photoshop CS5.

Statistical Analysis. Data were analyzed using Prism 6 (GraphPad) and presented as mean \pm SEM. Overall data were tested for normality and, after being deemed to have a normal distribution, were analyzed via one-way ANOVA followed by Dunnett's multiple comparison test. All comparisons were done between various groups and control. Sex differences in TgCRND8 mice were assessed by a post hoc analysis of the cohorts. Final images were created using Photoshop CS5 (Adobe).

RNaseq data. RNA sequencing data for TgCRND8 transgenic mice was downloaded from Synapse (doi: https://doi.org/10.7303/syn3157182). The gene count matrix was normalized for sex, and sequencing batch using robust linear regression (lqs method, MASS package in R) after filtering genes with less than 1 CPM in at least $50 \%$ of the samples, zero imputation and standardizing the covariates at their median value. Further details using this approach are described by Glusman et al. [72]. The normalized count matrix was used as input for analysis using DESeq2 [73]. Human RNA sequencing data was downloaded from Synapse (doi: https://doi.org/10. $7303 /$ syn5550404). Data for the moue studies is reported as FPKM with and for the human studies as cqn.

\section{Acknowledgements}

We would like to thank Center for Translational Research in

Neurodegenerative Disease, McKnight Brain Institute and Mayo Clinic College of Medicine for continuous support.

\section{Authors' contributions}

Y.L, P.C., T.E.G conceived and planned experiments, Y.L and P.C. performed animal experiments, B.B, V.O, X.L, T.L, P.E.C, D.R assisted with viral packaging, animal tissue collection and processing and staining, C.F, X.W, K.N.M, M.R, M.A, M.M.C, H.-D. L, N.D.P performed analysis of transcriptomic data from Tg mouse and AD human tissue, D.D provided human AD samples, Y.L and T.E.G wrote the manuscript. The author(s) read and approved the final manuscript.

\section{Funding}

Support provided by the NIH grants R01AG18454 (TEG, YL, PC),

R01AG046139 (TEG, NET, NP, CF) P50AG047266 (TEG), P30AG066506 (TEG). The RNAseq results published here are based on data obtained from the AD Knowledge Portal (https://adknowledgeportal.synapse.org/). Data collection for these studies was supported through funding by NIA grants P50 AG016574, R01 AG032990, U01 AG046139, R01 AG018023, U01 AG006576, U01 AG006786, R01 AG025711, R01 AG017216, R01 AG003949, NINDS grant R01 NS080820, CurePSP Foundation, and support from Mayo Foundation. Study data includes samples collected through the Sun Health Research Institute Brain and Body Donation Program of Sun City, Arizona.

\section{Availability of data and materials}

All data generated or analyzed during this study are included in this published article [and its supplementary information files]. Data that was generated by our consortium (https://adknowledgeportal.synapse.org/ Explore/Projects?Grant\%20Number=U01AG046139) within the larger AMPAD: Accelerating Medicines Partnership - Alzheimer's Disease Target Discovery and Preclinical Validation project (https://adknowledgeportal.synapse.org/ Explore/Programs?Program=AMP-AD).

\section{Declarations}

Ethics approval and consent to participate

All experiments using mice were carried out according to an Animal Use Protocol approved by the Institutional Animal Care and Use Committee at University of Florida.

\section{Consent for publication}

All authors have approved of the manuscript and agree with its submission.

\section{Competing interests}

The authors declare no conflict of interest.

\section{Author details}

${ }^{1}$ Department of Neuroscience and Neurology, Center for Translational Research in Neurodegenerative Disease, and McKnight Brain Institute, University of Florida, FL 32611 Gainesville, USA. ${ }^{2}$ Institute for Systems Biology, WA 98109 Seattle, USA. ${ }^{3}$ Department of Health Sciences Research, Mayo Clinic Florida, 32224 Jacksonville, FL, USA. ${ }^{4}$ Department of Neuroscience, Mayo Clinic, 32224 Jacksonville, FL, USA. ${ }^{5}$ Center for Bioinformatics, School of Computer Science and Engineering, Central South University, Hunan 410083 Changsha, People's Republic of China. ${ }^{6}$ Department of Neurology, Mayo Clinic, 32224 Jacksonville, FL, USA.

Received: 4 December 2020 Accepted: 26 April 2021

Published online: 06 May 2021

\section{References}

1. Hardy J. Toward Alzheimer therapies based on genetic knowledge. Annu Rev Med. 2004;55:15-25.

2. Golde TE. Overcoming translational barriers impeding development of Alzheimer's disease modifying therapies. J Neurochem. 2016;139(Suppl 2): 224-36.

3. Golde TE, Schneider LS, Koo EH. Anti-abeta therapeutics in Alzheimer's disease: the need for a paradigm shift. Neuron. 2011;69(2):203-13.

4. Ryan JM, Grundman M. Anti-amyloid-beta immunotherapy in Alzheimer's disease: ACC-001 clinical trials are ongoing. J Alzheimers Dis. 2009;17(2):243.

5. Winblad B, Andreasen N, Minthon L, Floesser A, Imbert G, Dumortier T, Maguire RP, Blennow K, Lundmark J, Staufenbiel M, et al. Safety, tolerability, and antibody response of active Abeta immunotherapy with CAD106 in patients with Alzheimer's disease: randomised, double-blind, placebocontrolled, first-in-human study. Lancet Neurol. 2012;11(7):597-604.

6. Lemere CA. Immunotherapy for Alzheimer's disease: hoops and hurdles. Mol Neurodegener. 2013;8:36.

7. Cummings J, Lee G, Mortsdorf T, Ritter A, Zhong K. Alzheimer's disease drug development pipeline: 2017. Alzheimers Dement (N Y). 2017;3(3):367-84

8. Sevigny J, Chiao P, Bussiere T, Weinreb PH, Williams L, Maier M, Dunstan R, Salloway S, Chen T, Ling Y, et al. The antibody aducanumab reduces Abeta plaques in Alzheimer's disease. Nature. 2016;537(7618):50-6. 
9. Vandenberghe R, Rinne JO, Boada M, Katayama S, Scheltens P, Vellas B, Tuchman M, Gass A, Fiebach JB, Hill D, et al. Bapineuzumab for mild to moderate Alzheimer's disease in two global, randomized, phase 3 trials. Alzheimers Res Ther. 2016;8(1):18.

10. Bohrmann B, Baumann K, Benz J, Gerber F, Huber W, Knoflach F, Messer J, Oroszlan K, Rauchenberger R, Richter WF, et al. Gantenerumab: a novel human anti-Abeta antibody demonstrates sustained cerebral amyloid-beta binding and elicits cell-mediated removal of human amyloid-beta. J Alzheimers Dis. 2012;28(1):49-69.

11. Lemere CA, Masliah E. Can Alzheimer disease be prevented by amyloid-beta immunotherapy? Nat Rev Neurol. 2010;6(2):108-19.

12. Rinne JO, Brooks DJ, Rossor MN, Fox NC, Bullock R, Klunk WE, Mathis CA, Blennow K, Barakos J, Okello AA, et al. 11 C-PiB PET assessment of change in fibrillar amyloid-beta load in patients with Alzheimer's disease treated with bapineuzumab: a phase 2, double-blind, placebo-controlled, ascending-dose study. Lancet Neurol. 2010;9(4):363-72.

13. Schneider LS, Mangialasche F, Andreasen N, Feldman H, Giacobini E, Jones R, Mantua V, Mecocci P, Pani L, Winblad B, et al. Clinical trials and late-stage drug development for Alzheimer's disease: an appraisal from 1984 to 2014. J Intern Med. 2014;275(3):251-83.

14. Anderson RM, Hadjichrysanthou C, Evans S, Wong MM. Why do so many clinical trials of therapies for Alzheimer's disease fail? Lancet. 2017; 390(10110):2327-9.

15. Honig LS, Vellas B, Woodward M, Boada M, Bullock R, Borrie M, Hager K, Andreasen N, Scarpini E, Liu-Seifert $H$, et al. Trial of solanezumab for mild dementia due to Alzheimer's disease. N Engl J Med. 2018;378(4):321-30.

16. Schwarz AJ, Sundell KL, Charil A, Case MG, Jaeger RK, Scott D, Bracoud L, Oh J, Suhy J, Pontecorvo MJ, et al. Magnetic resonance imaging measures of brain atrophy from the EXPEDITION3 trial in mild Alzheimer's disease. Alzheimers Dement (N Y). 2019:5:328-37.

17. Ferrero J, Williams L, Stella H, Leitermann K, Mikulskis A, O'Gorman J, Sevigny J. First-in-human, double-blind, placebo-controlled, single-dose escalation study of aducanumab (BIIB037) in mild-to-moderate Alzheimer's disease. Alzheimers Dement (N Y). 2016;2(3):169-76.

18. Budd Haeberlein S, O'Gorman J, Chiao P, Bussiere T, von Rosenstiel P, Tian $Y$, Zhu Y, von Hehn C, Gheuens S, Skordos L, et al. Clinical development of aducanumab, an anti-abeta human monoclonal antibody being investigated for the treatment of early Alzheimer's disease. J Prev Alzheimers Dis. 2017:4(4):255-63.

19. Selkoe DJ. Alzheimer disease and aducanumab: adjusting our approach. Nat Rev Neurol. 2019;15(7):365-6.

20. Schneider L. A resurrection of aducanumab for Alzheimer's disease. Lancet Neurol. 2020;19(2):111-2.

21. Knopman DS, Jones DT, Greicius MD. Failure to demonstrate efficacy of aducanumab: an analysis of the EMERGE and ENGAGE trials as reported by Biogen, December 2019. Alzheimers Dement. 2021;17(4):696-701. https:// doi.org/10.1002/alz.12213.

22. Logovinsky V, Satlin A, Lai R, Swanson C, Kaplow J, Osswald G, Basun H, Lannfelt L. Safety and tolerability of BAN2401-a clinical study in Alzheimer's disease with a protofibril selective Abeta antibody. Alzheimers Res Ther. 2016;8(1):14.

23. Golde TE, DeKosky ST, Galasko D. Alzheimer's disease: The right drug, the right time. Science. 2018;362(6420):1250-1.

24. Golde TE. Open questions for Alzheimer's disease immunotherapy. Alzheimers Res Ther. 2014;6(1):3.

25. Citron M. Alzheimer's disease: strategies for disease modification. Nat Rev Drug Discov. 2010;9(5):387-98.

26. Demattos RB, Lu J, Tang Y, Racke MM, Delong CA, Tzaferis JA, Hole JT, Forster BM, McDonnell PC, Liu F, et al. A plaque-specific antibody clears existing betaamyloid plaques in Alzheimer's disease mice. Neuron. 2012;76(5):908-20.

27. DeMattos RB, Bales KR, Cummins DJ, Paul SM, Holtzman DM. Brain to plasma amyloid-beta efflux: a measure of brain amyloid burden in a mouse model of Alzheimer's disease. Science. 2002;295(5563):2264-7.

28. Holtzman DM, Bales KR, Paul SM, DeMattos RB. Abeta immunization and anti-Abeta antibodies: potential therapies for the prevention and treatment of Alzheimer's disease. Adv Drug Deliv Rev. 2002;54(12):1603-13.

29. Morgan D. Mechanisms of A beta plaque clearance following passive A beta immunization. Neurodegener Dis. 2005;2(5):261-6.

30. Levites Y, Das P, Price RW, Rochette MJ, Kostura LA, McGowan EM, Murphy MP, Golde TE. Anti-Abeta42- and anti-Abeta40-specific mAbs attenuate amyloid deposition in an Alzheimer disease mouse model. J Clin Invest. 2006;116(1):193-201.
31. Liu-Seifert H, Case MG, Andersen SW, Holdridge KC, Aisen PS, Kollack-Walker $\mathrm{S}$, Siemers E. Delayed-start analyses in the phase 3 solanezumab EXPEDITION3 study in mild Alzheimer's disease. J Prev Alzheimers Dis. 2018; 5(1):8-14.

32. Levites $Y$, Jansen $K$, Smithson LA, Dakin R, Holloway VM, Das P, Golde TE. Intracranial adeno-associated virus-mediated delivery of anti-pan amyloid beta, amyloid beta40, and amyloid beta42 single-chain variable fragments attenuates plaque pathology in amyloid precursor protein mice. J Neurosci. 2006;26(46):11923-8.

33. Deane R, Sagare A, Hamm K, Parisi M, LaRue B, Guo H, Wu Z, Holtzman DM, Zlokovic BV. IgG-assisted age-dependent clearance of Alzheimer's amyloid beta peptide by the blood-brain barrier neonatal Fc receptor. J Neurosci. 2005:25(50):11495-503.

34. Finke JM, Banks WA. Modulators of IgG penetration through the bloodbrain barrier: Implications for Alzheimer's disease immunotherapy. Hum Antibodies. 2017;25(3-4):131-46.

35. Bacskai BJ, Kajdasz ST, McLellan ME, Games D, Seubert P, Schenk D, Hyman BT. Non-Fc-mediated mechanisms are involved in clearance of amyloid-beta in vivo by immunotherapy. J Neurosci. 2002;22(18):7873-8.

36. Wang A, Das P, Switzer RC III, Golde TE, Jankowsky JL. Robust amyloid clearance in a mouse model of Alzheimer's disease provides novel insights into the mechanism of amyloid-beta immunotherapy. J Neurosci. 2011; 31(11):4124-36

37. Xiang X, Werner G, Bohrmann B, Liesz A, Mazaheri F, Capell A, Feederle R, Knuesel I, Kleinberger G, Haass C. TREM2 deficiency reduces the efficacy of immunotherapeutic amyloid clearance. EMBO Mol Med. 2016;8(9):992-1004.

38. Chakrabarty P, Li A, Ceballos-Diaz C, Eddy JA, Funk CC, Moore B, DiNunno N, Rosario AM, Cruz PE, Verbeeck $C$, et al. IL-10 alters immunoproteostasis in APP mice, increasing plaque burden and worsening cognitive behavior. Neuron. 2015:85(3):519-33.

39. Chakrabarty P, Tianbai L, Herring A, Ceballos-Diaz C, Das P, Golde TE. Hippocampal expression of murine IL-4 results in exacerbation of amyloid deposition. Mol Neurodegener. 2012;7:36.

40. Chakrabarty P, Herring A, Ceballos-Diaz C, Das P, Golde TE. Hippocampal expression of murine TNFalpha results in attenuation of amyloid deposition in vivo. Mol Neurodegener. 2011:6:16.

41. Chakrabarty P, Jansen-West K, Beccard A, Ceballos-Diaz C, Levites Y, Verbeeck C, Zubair AC, Dickson D, Golde TE, Das P. Massive gliosis induced by interleukin-6 suppresses Abeta deposition in vivo: evidence against inflammation as a driving force for amyloid deposition. FASEB J. 2010;24(2): 548-59.

42. McAlpine FE, Lee JK, Harms AS, Ruhn KA, Blurton-Jones M, Hong J, Das P, Golde TE, LaFerla FM, Oddo $S$, et al. Inhibition of soluble TNF signaling in a mouse model of Alzheimer's disease prevents pre-plaque amyloidassociated neuropathology. Neurobiol Dis. 2009:34(1):163-77.

43. Ulrich JD, Finn MB, Wang Y, Shen A, Mahan TE, Jiang $H$, Stewart FR, Piccio L, Colonna M, Holtzman DM. Altered microglial response to Abeta plaques in APPPS1-21 mice heterozygous for TREM2. Mol Neurodegener. 2014;9:20.

44. Heneka MT, Kummer MP, Latz E. Innate immune activation in neurodegenerative disease. Nat Rev Immunol. 2014;14(7):463-77.

45. Golde TE. Harnessing immunoproteostasis to treat neurodegenerative disorders. Neuron. 2019;101(6):1003-15.

46. Guillot-Sestier MV, Doty KR, Gate D, Rodriguez J Jr, Leung BP, Rezai-Zadeh K, Town T. II10 deficiency rebalances innate immunity to mitigate Alzheimerlike pathology. Neuron. 2015;85(3):534-48.

47. Guillot-Sestier MV, Doty KR, Town T. Innate immunity fights Alzheimer's disease. Trends Neurosci. 2015:38(11):674-81.

48. Vom Berg J, Prokop S, Miller KR, Obst J, Kalin RE, Lopategui-Cabezas I, Wegner A, Mair F, Schipke CG, Peters O, et al. Inhibition of IL-12/L-23 signaling reduces Alzheimer's disease-like pathology and cognitive decline. Nat Med. 2012;18(12):1812-9.

49. El Khoury J, Toft M, Hickman SE, Means TK, Terada K, Geula C, Luster AD. $\mathrm{Ccr} 2$ deficiency impairs microglial accumulation and accelerates progression of Alzheimer-like disease. Nat Med. 2007;13(4):432-8.

50. Ardura-Fabregat A, Boddeke E, Boza-Serrano A, Brioschi S, Castro-Gomez S, Ceyzeriat K, Dansokho C, Dierkes T, Gelders G, Heneka MT, et al. Targeting neuroinflammation to treat Alzheimer's disease. CNS Drugs. 2017;31(12): 1057-82.

51. Scholtzova H, Chianchiano P, Pan J, Sun Y, Goni F, Mehta PD, Wisniewski T. Amyloid beta and Tau Alzheimer's disease related pathology is reduced by toll-like receptor 9 stimulation. Acta Neuropathol Commun. 2014;2:101. 
52. Montgomery SL, Mastrangelo MA, Habib D, Narrow WC, Knowlden SA, Wright TW, Bowers WJ. Ablation of TNF-RI/RII expression in Alzheimer's disease mice leads to an unexpected enhancement of pathology: implications for chronic pan-TNF-alpha suppressive therapeutic strategies in the brain. Am J Pathol. 2011;179(4):2053-70.

53. Shi Y, Manis M, Long J, Wang K, Sullivan PM, Remolina Serrano J, Hoyle R, Holtzman DM. Microglia drive APOE-dependent neurodegeneration in a tauopathy mouse model. J Exp Med. 2019;216(11):2546-61.

54. Spangenberg E, Severson PL, Hohsfield LA, Crapser J, Zhang J, Burton EA, Zhang Y, Spevak W, Lin J, Phan NY, et al. Sustained microglial depletion with CSF1R inhibitor impairs parenchymal plaque development in an Alzheimer's disease model. Nat Commun. 2019;10(1):3758.

55. Gratuze $M$, Leyns $C E$, Sauerbeck AD, St-Pierre MK, Xiong M, Kim N, Serrano $J R$, Tremblay ME, Kummer TT, Colonna M, et al. Impact of TREM2R47H variant on tau pathology-induced gliosis and neurodegeneration. J Clin Invest. 2020;130(9):4954-68.

56. Jay TR, Miller CM, Cheng PJ, Graham LC, Bemiller S, Broihier ML, Xu G Margevicius D, Karlo JC, Sousa GL, et al. TREM2 deficiency eliminates TREM2 + inflammatory macrophages and ameliorates pathology in Alzheimer's disease mouse models. J Exp Med. 2015;212(3):287-95.

57. Bolos M, Llorens-Martin M, Perea JR, Jurado-Arjona J, Rabano A, Hernandez F, Avila J. Absence of CX3CR1 impairs the internalization of Tau by microglia. Mol Neurodegener. 2017;12(1):59.

58. Castillo-Ruiz A, Mosley M, George AJ, Mussaji LF, Fullerton EF, Ruszkowski EM, Jacobs AJ, Gewirtz AT, Chassaing B, Forger NG. The microbiota influences cell death and microglial colonization in the perinatal mouse brain. Brain Behav Immun. 2018;67:218-29.

59. Erny $D$, Hrabe de Angelis AL, Jaitin D, Wieghofer P, Staszewski O, David E, Keren-Shaul H, Mahlakoiv T, Jakobshagen K, Buch T, et al. Host microbiota constantly control maturation and function of microglia in the CNS. Nat Neurosci. 2015;18(7):965-77.

60. Wan YW, Al-Ouran R, Mangleburg CG, Perumal TM, Lee TV, Allison K, Swarup V, Funk CC, Gaiteri C, Allen M, et al. Meta-analysis of the Alzheimer's disease human brain transcriptome and functional dissection in mouse models. Cell Rep. 2020;32(2):107908.

61. Verbeeck C, Carrano A, Chakrabarty P, Jankowsky UL, Das P. Combination of Abeta suppression and innate immune activation in the brain significantly attenuates amyloid plaque deposition. Am J Pathol. 2017;187(12):2886-94.

62. Levites Y, Smithson LA, Price RW, Dakin RS, Yuan B, Sierks MR, Kim J, McGowan E, Reed DK, Rosenberry TL, et al. Insights into the mechanisms of action of anti-Abeta antibodies in Alzheimer's disease mouse models. FASEB J. 2006;20(14):2576-8.

63. Herline K, Prelli F, Mehta P, MacMurray C, Goni F, Wisniewski T. Immunotherapy to improve cognition and reduce pathological species in an Alzheimer's disease mouse model. Alzheimers Res Ther. 2018;10(1):54.

64. Dodart JC, Bales KR, Gannon KS, Greene SJ, DeMattos RB, Mathis C, DeLong CA, Wu S, Wu X, Holtzman DM, et al. Immunization reverses memory deficits without reducing brain Abeta burden in Alzheimer's disease model. Nat Neurosci. 2002;5(5):452-7.

65. Jenkins RW, Barbie DA, Flaherty KT. Mechanisms of resistance to immune checkpoint inhibitors. Br J Cancer. 2018;118(1):9-16.

66. Zhou Y, Song WM, Andhey PS, Swain A, Levy T, Miller KR, Poliani PL, Cominelli M, Grover S, Gilfillan S, et al. Human and mouse single-nucleus transcriptomics reveal TREM2-dependent and TREM2-independent cellular responses in Alzheimer's disease. Nat Med. 2020;26(1):131-42.

67. Sebastian Monasor L, Muller SA, Colombo AV, Tanrioever G, Konig J, Roth S, Liesz A, Berghofer A, Piechotta A, Prestel M, et al. Fibrillar Abeta triggers microglial proteome alterations and dysfunction in Alzheimer mouse models. Elife. 2020;9:e54083.

68. Sala Frigerio C, Wolfs L, Fattorelli N, Thrupp N, Voytyuk I, Schmidt I, Mancuso $\mathrm{R}$, Chen WT, Woodbury ME, Srivastava G, et al. The major risk factors for Alzheimer's disease: age, sex, and genes modulate the microglia response to Abeta plaques. Cell Rep. 2019;27(4):1293-306 e1296

69. Cavaliere C, Tramontano L, Fiorenza D, Alfano V, Aiello M, Salvatore M. Gliosis and neurodegenerative diseases: the role of PET and MR imaging. Front Cell Neurosci. 2020;14:75.

70. Ramsden M, Kotilinek L, Forster C, Paulson J, McGowan E, SantaCruz K, Guimaraes A, Yue M, Lewis J, Carlson G, et al. Age-dependent neurofibrillary tangle formation, neuron loss, and memory impairment in a mouse model of human tauopathy (P301L). J Neurosci. 2005;25(46):10637-47.

71. Moore BD, Chakrabarty P, Levites Y, Kukar TL, Baine AM, Moroni T, Ladd TB, Das P, Dickson DW, Golde TE. Overlapping profiles of Abeta peptides in the
Alzheimer's disease and pathological aging brains. Alzheimers Res Ther. 2012;4(3):18

72. Glusman G, Caballero J, Robinson M, Kutlu B, Hood L. Optimal scaling of digital transcriptomes. PLoS One. 2013;8(11):e77885.

73. LoveMI, Huber W, AndersS. Moderated estimation of fold change and dispersion for RNA-seq data with DESeq2. Genome Biol . 20174;15(12).

\section{Publisher's Note}

Springer Nature remains neutral with regard to jurisdictional claims in published maps and institutional affiliations.

\section{Ready to submit your research? Choose BMC and benefit from:}

- fast, convenient online submission

- thorough peer review by experienced researchers in your field

- rapid publication on acceptance

- support for research data, including large and complex data types

- gold Open Access which fosters wider collaboration and increased citations

- maximum visibility for your research: over $100 \mathrm{M}$ website views per year

At $\mathrm{BMC}$, research is always in progress.

Learn more biomedcentral.com/submissions 